\title{
Do We Need Anti-Prionic Compounds to Treat Alzheimer's Disease?
}

\author{
Dieter Willbold ${ }^{1,2, *(\mathbb{D})}$ and Janine Kutzsche ${ }^{1}$ \\ 1 Institute of Complex Systems, Structural Biochemistry (ICS-6), Forschungszentrum Jülich, 52425 Jülich, \\ Germany; j.kutzsche@fz-juelich.de \\ 2 Institut für Physikalische Biologie, Heinrich-Heine-Universität Düsseldorf, 40225 Düsseldorf, Germany \\ * Correspondence: d.willbold@fz-juelich.de; Tel.: +49-2461-612100; Fax: +49-2461-612023
}

Academic Editor: Gal Bitan

Received: 21 May 2019; Accepted: 13 June 2019; Published: 15 June 2019

\begin{abstract}
Background: While phase III clinical trials for the treatment of Alzheimer's disease (AD) keep failing regardless of the target, more and more data suggest that the toxic protein assemblies of amyloid-beta protein $(A \beta)$ and tubulin binding protein (TAU) behave like prions. Irrespective of the question of whether $\mathrm{AD}$ is theoretically or practically contagious, the presence of a self-replicating toxic etiologic agent in the brains of $\mathrm{AD}$ patients must have decisive consequences for drug development programs and clinical trial designs. Objectives: We intend to challenge the hypothesis that the underlying etiologic agent of $\mathrm{AD}$ is behaving prion-like. We want to discuss whether the outcome of clinical trials could have been predicted based on this hypothesis, and whether compounds that directly disassemble the toxic prion could be more beneficial for AD treatment. Method: We collected publicly accessible pre-clinical efficacy data of $A \beta$ targeting compounds that failed or still are in phase III clinical trials. We describe the desired properties of an anti-prionic compound and compare it the properties of past and current phase III drug candidates. Results: We could not find convincing and reproducible pre-clinical efficacy data of past and current phase III drug candidates on cognition other than in preventive treatment settings. The desired properties of an anti-A $\beta$-prionic compound are fulfilled by the drug candidate RD2, which has been developed to directly disassemble toxic $\mathrm{A} \beta$ oligomers. Conclusion: RD2 is the first anti-prionic drug candidate. It is able to enhance cognition and impede neurodegeneration in three different transgenic AD mouse models, even under truly non-preventive conditions and even when applied orally. In addition, it is safe in humans.
\end{abstract}

Keywords: Alzheimer's disease; amyloid $\beta$; $A \beta$ oligomers; anti-prionic; oral treatment; D-enantiomeric peptides

\section{Alzheimer's Disease}

Alzheimer's disease (AD) is a progressive neurodegenerative disorder which is associated with cognitive deficits, neurodegeneration as well as the aggregation of amyloid-beta protein $(A \beta)$ and aggregation of TAU. The TAU protein (tubulin binding protein) is a microtubule-associated protein coded by the MAPT gene, which is localized in humans on chromosome 17 [1]. It exists in at least six isoforms originating from alternative mRNA splicing [2]. Mutations in the MAPT gene have been associated with several neurodegenerative diseases, but not with $\mathrm{AD}$ [3]. $\mathrm{A} \beta$ is a proteolytic fragment of the amyloid-beta precursor protein (APP) produced by beta and gamma secretase cleavages [4]. APP processing leads to various variants of $A \beta$, differing at their carboxy and amino-terminal ends (A $\beta$ 1-39, $A \beta 1-40, A \beta 1-42$, and $A \beta 1-43$ as well as amino-terminal truncated and pyro-Glu-A $\beta$ species) and with quite different aggregation propensities. 
The resulting $A \beta$ assemblies include soluble low molecular weight oligomers, protofibrils, and insoluble, fibrillar aggregates. Fibrillar $\mathrm{A} \beta$ is the major component of extracellular senile plaques, which are one of the histopathological hallmarks seen in the brains of AD patients.

There is overwhelming genetic data pointing to a decisive role of $A \beta$ in whatever state, form or condition, in the development and progression of AD. Mutations in genes coding for the amyloid precursor protein APP or presenilin 1 (PS1), the catalytic part of the $\gamma$-secretase complex, often lead to early onset familial AD cases [5]. Mutations in the gene coding for TAU, however, do not lead to $\mathrm{AD}$, but can lead to other disorders. Based on these findings more than 25 years ago, the amyloid hypothesis was formulated by Hardy and Higgins [6]. They postulated that accumulation of A $\beta$ in the brain is the primary cause driving $A D$ pathogenesis triggering all other neurodegenerative processes, including the formation of neurofibrillary tangles that lead to the loss of memory and other cognitive abilities [7]. On the basis of this theory, disease-modifying treatments were developed which should interrupt early pathologic events by reducing $A \beta 42$ production ( $\beta$ - and $\gamma$-secretase inhibitors), increasing amyloid plaque clearance (immunotherapy) and decreasing plaque formation ( $A \beta_{42}$ lowering agents like tarenflurbil and inhibitors of amyloid aggregation tramiprosate), thus preventing later pathologic processes.

Despite this enormous scientific and economic effort, none of the drug candidates which were developed based on the amyloid hypothesis were successful in phase III clinical trials with beneficial effects on cognition decline. Currently, more than 20 million patients worldwide are affected which makes an effective therapy for $\mathrm{AD}$ perhaps one of the greatest unmet medical needs modern medicine is facing. At present the available medications (cholinesterase-inhibitors (ChEIs) and the N-methyl-d-aspartate (NMDA) receptor antagonist memantine) are only treating symptoms in a very limited way with unpleasant side effects [8] and are not able to slow disease progression. In addition, $\mathrm{AD}$ is not only a burden for patients, their relatives and care givers, but it also is a threat to healthcare systems.

There is agreement that $\mathrm{A} \beta$ monomers are not toxic. Also, it is known for a long time already that plaque load does not correlate with AD progression [9]. Thus, especially over the past years, it has been postulated that the plaques themselves do not have the most deleterious effect, but rather small, mobile and soluble $A \beta$ assemblies. Indeed, studies in recent years have strengthened the hypothesis that these so called $A \beta$ oligomers are the major neurotoxic agent responsible for disease development and progression [10-14]. Furthermore, there is more and more evidence that $A \beta$ oligomers, or at least sub-fractions of them, are able to replicate in a prion-like fashion [15-17].

Since A $\beta$-oligomers have been claimed to be the disease causing agent, there have been several attempts made to increase their clearance by passive or active immunization [11,18,19]. Although those attempts did show promising pre-clinical outcomes at least on plaque pathology and sometimes also on cognition under preventive treatment settings [20-22], none of these were beneficial for cognition in clinical trials yet [23-25]. Besides the missing efficacy to significantly decelerate cognitive decline or to ameliorate memory deficits, so-called amyloid-related imaging abnormalities (ARIA-E or ARIA-H) occurred in several cases (potentially indicating for example microhemorrhages or meningoencephalitis), representing some of the major severe side effects of $A \beta$-immunotherapy for Alzheimer's disease [26,27], which is of concern especially because the prospective treatment is envisioned as life-long.

\section{A $\beta$ Aggregation}

Aggregation of $A \beta$ monomers into fibrils and other assembly species is thermodynamically favored. This is obvious, because otherwise it would simply not happen neither in the test tube nor in the brain. The formation of the first stable assembly is, however, kinetically very unfavored. This can be seen in every single Thioflavin T (ThT) fluorescence measured A $\beta$ aggregation kinetic, which typically looks like the one shown in Figure 1. There is always a lag phase, followed by a steep increase 
in ThT-positive assembly formation and a saturation plateau at the end, when the monomer building blocks become depleted and limiting.

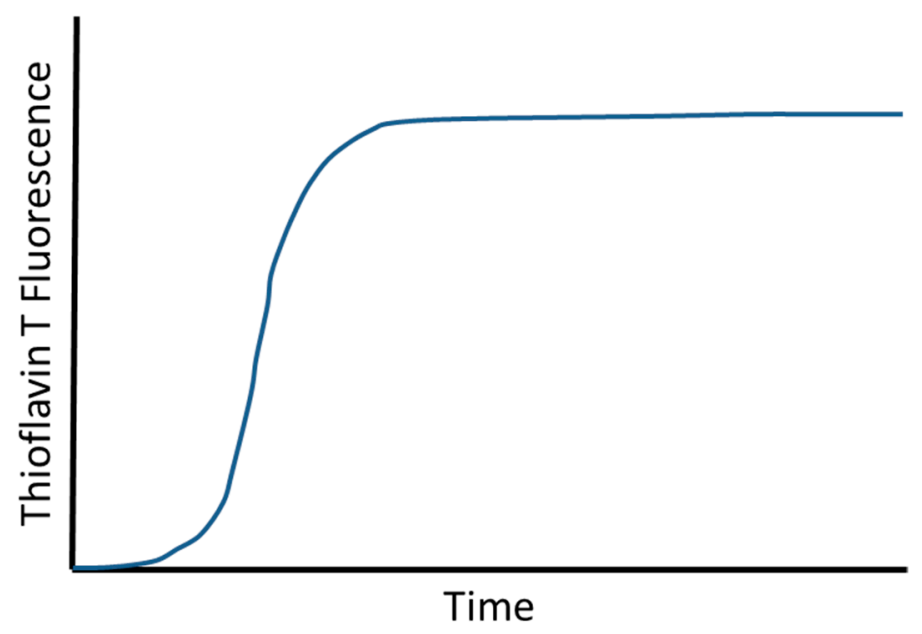

Figure 1. Scheme of a typical amyloid-beta protein $(A \beta)$ aggregation assay result. Even at high micromolar $\mathrm{A} \beta$ concentrations, there is always a lag phase in ThT fluorescence detected $\mathrm{A} \beta$ aggregation experiments, followed by a steep increase in ThT-positive assembly formation and a saturation plateau at the end, when the monomer building blocks become depleted and limiting.

This kind of aggregation behavior has been described a thousand-fold and analyzed in great detail $[28,29]$. It very much resembles a bacterial growth curve. The steep (logarithmic) increase in ThT fluorescence indicates the presence of ThT-positive A $\beta$ species that are capable for self-supported auto-catalytic growth and/or amplification of themselves. The big difference to a bacterial growth curve is of course that the start of the steep "growth" phase does not require inoculation with bacteria. This in turn suggests that the ThT-positive A $\beta$ species capable of self-supported auto-catalytic growth and/or amplification of themselves can spontaneously form from $A \beta$ monomers. This is supported by the observation that the length of the lag phase in the ThT assay, which starts with an initial period devoid of such $A \beta$ assemblies can be drastically shorted by adding $A \beta$ aggregate "seeds" that can be taken for example from other aggregation experiments at later stages of the experiment. But, as said in the beginning of this paragraph, this kind of $A \beta$ aggregation behavior has been analyzed in much greater detail $[28,29]$ and is described in a much more simplified version here only for educational and reasons and to prepare for the following thoughts on the implications for drug development and clinical trial designs.

The critical concentration of $\mathrm{A} \beta$ for its aggregation has been described as $90 \mathrm{nM}$ [30]. Thus, in order to investigate $A \beta$ aggregation in vitro, it is necessary to study $A \beta$ solutions in micromolar concentrations or even higher. Under physiological conditions (approximately $1 \mathrm{nM} \mathrm{A} \beta$ ), aggregation is practically not observable, again underlining that the formation of the (first) $A \beta$ seed is strongly kinetically unfavored. It also is line with the expectation that formation of the smallest stable $A \beta$ assembly (seed) requires many monomer units to meet at the same time at the same place and thus is a high order reaction. Investigation of $A \beta$ in a matrix-free solution yielded a pentamer or hexamer as the smallest populated and detectable assembly size [31], which nicely agrees with the "minimal fibril unit" of six A $\beta$ monomer units defined in the high resolution $A \beta$ fibril structure [32]. There have been reports on observed dimers, trimers, and tetramers as well, but those studies rely on sodium dodecylsulfate polyacrylamide gel electrophoresis (SDS PAGE) analysis of species with unknown SDS/A $\beta$ ratios or on chemical cross-linking studies that would also allow other interpretations. For the following over-simplified scheme (Figure 2) and its description, however, the exact number of monomer units required for the formation of the minimal stable assembly is not even so important. 




APP
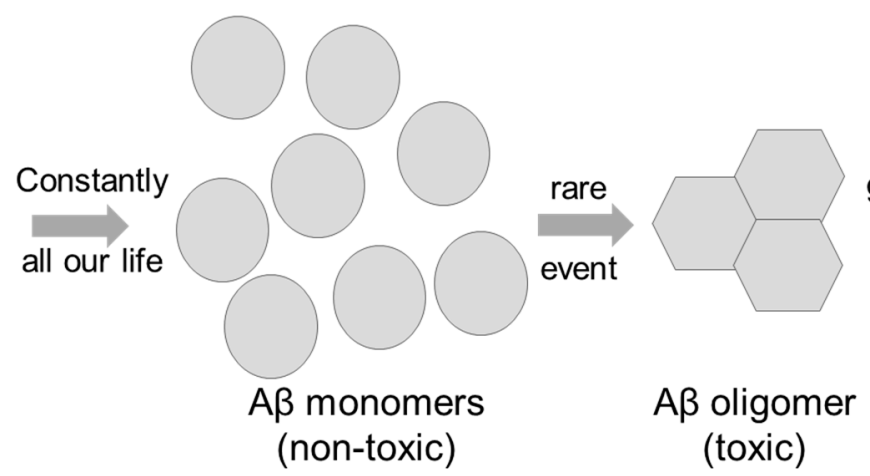

growth and



replication



Figure 2. From left to right: Throughout our life time, $A \beta$ monomers are constantly formed from the amyloid-beta precursor protein amyloid precursor protein (APP) by cleavage of betaand gamma-secretases. Under physiological conditions (circa $1 \mathrm{nM} \mathrm{A} \beta$ ) the formation of a stable $\mathrm{A} \beta$ oligomer is a very rare event, because several $A \beta$ monomers have to meet in one place at the same time. This is a high order reaction, which is extremely dependent on the $A \beta$ monomer concentration (e.g., to the sixth power). For rare things to happen, however, one only needs to wait long enough, explaining why life age is the most important risk factor for AD. Genetic disposition (familial AD cases and Trisomy 21) can lead to higher $A \beta$ concentrations, making the formation of the first oligomer seed more likely to happen and thus occurs earlier in life. Once the first $A \beta$ oligomer seed has been formed, it can further grow by consecutively consuming one $A \beta$ monomer after the other. This is a kinetically favored first order reaction with a rate much less dependent on the $A \beta$ monomer concentration. $A \beta$ oligomers can break into smaller assemblies that grow again by consuming $A \beta$ monomers. This is nothing else than a replication competent $A \beta$ assembly containing $A \beta$ monomer subunits in defined conformation, which is different from the intrinsically disordered native $A \beta$ monomer conformation. In the scheme, different shapes symbolize different conformations of $A \beta$. For the sake of simplicity, the possibility of different $A \beta$ assembly species containing $A \beta$ monomers in even more different defined conformations has not been included in the scheme. This would be analogous to the concept of different existing prion strains with different properties. Please note that also the concept of secondary nucleation, which describes the oligomer-assisted seed formation in the vicinity of pre-existing assemblies, has not been included in this over-simplified scheme.

Accumulating evidence implicates a role for prion-like features in a number of neurodegenerative disorders, including AD. The etiologic agent responsible for the development and progression of the disease has been suggested to be a prion, prionoid or prion-like. There is more and more evidence that this assumption is principally correct [33,34]. This review does not intend to discuss or decide which name is the correct one. It is also not the right place to discuss whether this also means that the respective disease is contagious or not. The assumption that the $\mathrm{A} \beta$ aggregates underlying the disease progression behave like prions, however, has very important and decisive consequences for the development of a successful treatment strategy. For the rest of this review we will use the shortest possible name "prion" for such a replicating toxic $A \beta$ assembly.

\section{Did the Concept of a Replicating Toxic A $\beta$ Assembly Predict the Outcomes of the Failed Phase III Clinical Trials?}

Until now, we have witnessed many failures of compounds in clinical trials that were aiming to reduce $A \beta$ formation (e.g., beta and gamma secretase inhibitors or modulators [35]) or compounds which increase the clearance of $A \beta$ for example by passive or active immunization against different $A \beta$ species [36]. Decreasing total $A \beta$ levels may possibly be appropriate to make the formation of the first prion-like behaving oligomer less probable and thus to occur much later in life. Such a strategy, however, may only be preventively beneficial and thus "only" be potentially helpful to prevent or postpone the disease onset. 
Once $A \beta$ oligomers have been formed and are already replicating in the brain, however, the reduction of total $A \beta$ monomer substrates (by $20 \%$ to $30 \%$ ), as envisioned by the use of beta- and gamma-secretase inhibitors and modulators, might in the best case slow down replication of prions, but is probably not enough to significantly slow disease progression. Taken from birth, beta- and gamma-secretase inhibitors and modulators could possibly delay the formation of the first $A \beta$ prion seed. The situation in each AD patient's brain is certainly post-seed-formation and prevention is too late. To the best of our knowledge, published pre-clinical data on past and current phase III betaand gamma-secretase inhibitors and modulators have only shown efficacy on plaque load reduction. Beneficial effects on cognition have been obtained (if at all) only in purely preventive settings. Thus, based on the above described hypothesis that the etiologic agent for AD is a replicating toxic $A \beta$ species, the failure of beta- and gamma-secretase inhibitors and modulators under non-preventive treatment settings-as it is in the patient—can, or even must be, expected to fail in the clinics.

The concept behind using anti-A $\beta$-antibodies (AAbs) is the expectation that they reach and find their target and induce its degradation by cells of the immune system (microglia and astrocytes) [37]. Obviously, $A \beta$ monomer and $A \beta$ fibril binding $A A b s$ will not prevent $A \beta$ oligomer prions from replicating. $A A$ bs that are $A \beta$ oligomer specific will, if they reach the target organ, bind to $A \beta$ oligomers. They do not, however, destroy them. Thermodynamically, they will even stabilize them. AAbs rely on the immune system, which is not very efficient anymore in the target age group, anyway [38]. Much more importantly, it has not been shown so far that AAbs bound to A $\beta$ oligomers have led to the ultimate disassembly or degradation of the bound oligomer. Further, AAbs are not very efficient in penetrating the blood brain barrier (BBB). Thus, it is not so surprising that to the best of our knowledge, published pre-clinical data on anti-A $\beta$-antibodies, which failed or are currently in phase III studies, have shown only efficacy on plaque load reduction. Beneficial reproducible effects on cognition have been obtained (if at all) only in preventive settings. This is exactly what one could have expected based on the above described hypothesis that the etiologic agent for $\mathrm{AD}$ is a replicating toxic $\mathrm{A} \beta$ species. Moreover, it is not clear what the disease relevant $A \beta$ oligomer species looks like and whether a given antibody will bind it. Also, as it is known from prion protein strains, there might be an issue with the development of resistance to antibodies that are specific for a certain prion species [39].

Thus, with the current knowledge one could have already predicted from published pre-clinical data that treatment of AD patients with beta- and gamma-secretase inhibitors and modulators or with anti-A $\beta$-antibodies will probably not be beneficial for cognition, which is the crucial property for patient benefit and thus also for competent authorities for market admission and reimbursement. The most efficient ways to fight a replicating pathogen is either active immunization or applying substances that directly kill or destroy the pathogen, e.g., antibiotics in the case of bacterial pathogens. Active immunization against body's own proteins, like $A \beta$ has proven already, bears the risk of severe side effects.

Therefore, it is essential to directly eliminate $A \beta$ oligomers by disassembling them into $A \beta$ monomers or by converting them into other $A \beta$ species that are not toxic.

It is obvious that the suggested therapeutic strategy to develop anti-prionic compounds and the underlying hypothesis of a self-replicating toxic protein assembly (prion) being the etiologic agent of $\mathrm{AD}$ needs to be evaluated in future proof of concept $(\mathrm{PoC})$ studies in $\mathrm{AD}$ patients. The etiologic agent being a prion, however, would have predicted the clinical failures of the drug candidates tested so far in phase III.

Other approaches including anti-aggregation agents ( $\beta$-sheet breakers e.g., HPYD or aggregation inhibitor like ALZ-801), anti-inflammatory agents (e.g., MLC901), Tau protein aggregation inhibitors (e.g., TRx0237), neuroprotective agents and autophagy inducers are currently in different phases of the Alzheimer's disease drug development pipeline, for example reviewed in detail in Cummings et al. 2019 [40], on https://clinicaltrials.gov, https://www.alzforum.org or https://www.alz.org/. Their proof for a beneficial impact on the progression of the disease is still pending. 


\section{Consequences of the Concept of a Replicating Toxic A $\beta$ Assembly as the Etiologic Agent of AD for the Potential Treatment of AD}

What is essential for efficient disease treatment is the complete extinction of the toxic prion species. Thus, anti-prionics are needed that reach the brain and are able to directly destroy prion particles and disassemble them into natively folded monomeric $\mathrm{A} \beta$ molecules.

Thus, we propose the development and application of anti-prionic compounds to treat prion diseases in general. What properties would such a compound need to have?

During the past years, we have therefore developed such an anti-prionic for $\mathrm{A} \beta$ prions. The compound $\mathrm{RD} 2$ was developed and optimized for stabilizing $\mathrm{A} \beta$ monomers in their native (intrinsically disordered) conformation to directly destabilize, disassemble and ultimately eliminate toxic $A \beta$ oligomers via their direct disruption, rather than by relying on the immune system for their destruction. The mode of action is as follows (see Figure 3 from right to left). When the compound RD2 is approaching the prion assembly, it will interact with one of the $A \beta$ monomer subunits, thereby trying to change its conformation towards the native one that does not perfectly fit to the rest of the prion. Thus, the prion particle is destabilized already. Each additional drug molecule will interact with more $A \beta$ monomer subunits, further destabilizing and ultimately destroying and fully disassembling the $A \beta$ prion particle. We have proven this kind of target engagement in vitro and shown that this oligomer disassembly is highly cooperative (Hill coefficient: 3) [41]. We have also shown that the drug candidate RD2 is efficient already at clearly sub-stoichiometric ratios. Both properties can be expected from this mechanism of action.

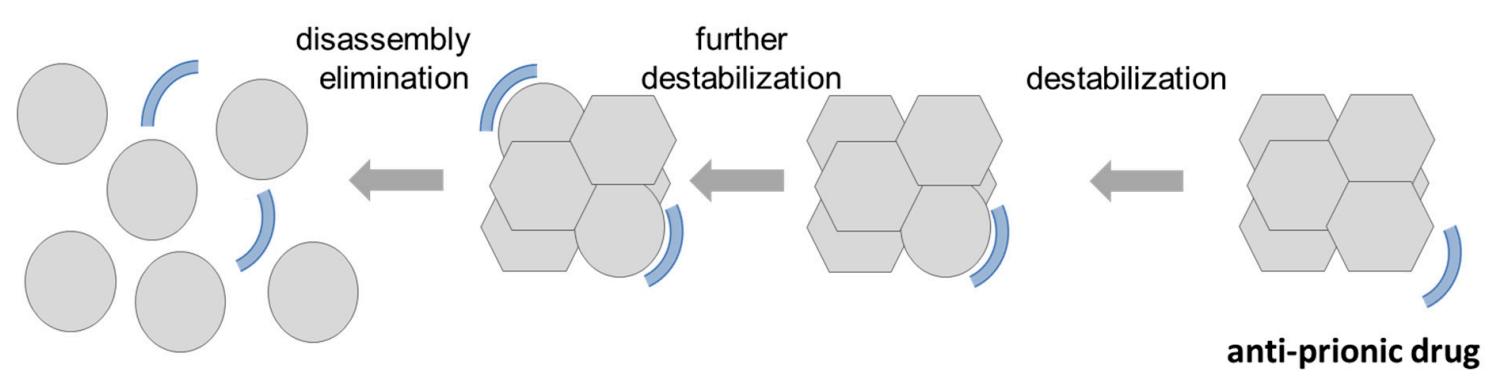

Figure 3. Suggested mode of action of an anti-prionic compound (from right to left): The desired anti-prionic compound should preferentially bind $\mathrm{A} \beta$ monomers and stabilize them in their native, intrinsically disordered conformation. This can be envisioned in a transient manner and is not necessarily in a 1:1 stoichiometry. When the compound is approaching the prion assembly, it will interact with one of the $\mathrm{A} \beta$ monomer subunits and thereby pushing its conformation towards the native one that does not perfectly fit to the rest of the prion particle. Thus, the prion particle is already destabilized a bit by this interaction. Each additional anti-prionic drug molecule will interact with further $A \beta$ monomer subunits, further destabilizing and ultimately destroying and fully disassembling the $\mathrm{A} \beta$ prion particle. From a physicochemical and biophysical perspective, one would expect the action to be highly cooperative, clearly sub-stoichiometric (relative to the number of $A \beta$ monomer subunits) and possibly even catalytic, because the drug molecules are not consumed during the prion destruction.

The expected clinical impact/benefit of an anti-prionic therapy would be the deceleration or even stop of the cognitive decline and a partial recovery from cognitive dysfunctions. This would open up the possibility for patients to take care of their own daily living, as well as increase their length of live and especially their quality of life, which would be an enormous improvement for patients and their families. The socioeconomic impact will also be substantial, including cost reductions for healthcare systems. The idea to eradicate the replicative/infective agent during the treatment allows treatment periods that are not necessarily life-long. This would be of great advantage as life-long treatments have to be well-balanced between optimal efficacy and minimal undesirable side effects in order to maintain a high quality of life. Moreover, this approach aims to specifically eliminate all 
toxic oligomers regardless of any conformation or potential strain by stabilizing $\mathrm{A} \beta$ monomers in an aggregation incompetent conformation.

We have confirmed this mechanism of action (MoA) additionally by a successful target engagement in vivo [42]. RD2 also has proven pharmacodynamical activity in several animal models carried out independently in multiple laboratories. Treatments with orally applied RD2 led to enhanced cognition in two different $\mathrm{AD}$ mouse models $\left(\mathrm{APP}_{\text {swe }} / \mathrm{PS} 1 \triangle \mathrm{E} 9\right.$ and $\left.\mathrm{APP} \mathrm{SL}\right)[42,43]$. Cognition improvement was even demonstrated in old-aged AD mice with severe cognition deficits and full-blown AD-associated pathology [42]. Furthermore, RD2 led to a significant deceleration of the motor neurodegenerative phenotype of pyroglutamate-A $\beta$ expressing TBA2.1 AD-mice after oral administration [44].

In parallel, we were investigating potential alternative MoAs that could possibly also explain the beneficial pre-clinical treatment outcomes. One possible additional MoA would be the displacement of $\operatorname{PrP}$ from $\mathrm{A} \beta$ oligomers by RD2. It was shown previously that the cellular prion protein $\left(\operatorname{PrP}^{\mathrm{C}}\right)$ mediates toxicity of $\mathrm{A} \beta$ oligomers $[45,46]$. To examine if $\mathrm{RD} 2$ competes with $\mathrm{PrP}^{\mathrm{C}}$ for binding to $\mathrm{A} \beta$ oligomers, we analyzed the $\mathrm{A} \beta(1-42)$ oligo/huPrP(23-230) hetero-assembly formation in the presence and absence of RD2 and revealed, that RD2 interferes with the hetero-assembly but only when A $\beta(1-42)$ oligo is preincubated with RD2 before huPrP application [47], which has no relevance for a therapeutic treatment after disease onset.

A pharmacokinetic study using ${ }^{3} \mathrm{H}$-labeled RD2 yielded high oral bioavailability and penetration of the blood brain barrier [48]. In particular, oral administration resulted in a maximal brain concentration per dose $\left(C_{\max } / \mathrm{D}\right)$ of $0.06(\mu \mathrm{g} / \mathrm{g}) /(\mathrm{mg} / \mathrm{kg})$, a brain/plasma ratio of about 1 , a bioavailability in the brain of $100 \%$ and very low ${ }^{3} \mathrm{H}-\mathrm{RD} 2$ levels in liver, kidney and plasma. Interestingly, in the brain ${ }^{3} \mathrm{H}-\mathrm{RD} 2$ was found after oral administration in amounts similar to all other tested administration routes (i.v., i.p., s.c.). Furthermore, RD2 showed a small elimination constant $\left(0.0002 \mathrm{~min}^{-1}\right)$ and long terminal half-life of $58 \mathrm{~h}$ in plasma. It also exhibits high bioavailability $\left(\mathrm{F}_{\mathrm{AUC}-28}\right)$ in plasma of about $76.5 \%$ [48]. In the liver and kidneys, oral administration resulted in a maximal concentration per dose $\left(C_{\max } / \mathrm{D}\right)$ of $0.09(\mu \mathrm{g} / \mathrm{g}) /(\mathrm{mg} / \mathrm{kg})$.

For D3, the lead compound of RD2, it was shown that adsorptive-mediated transcytosis (AMT) is involved in the transport of D3 across the BBB [49]. AMT has also been proposed for the transport of several arginine-rich peptides, such as the basic peptide derived from the human immunodeficiency virus type 1 (HIV-1) Tat proteins, across the BBB [50]. In extensive in vitro stability studies, we demonstrated that RD2 is remarkably resistant against metabolization in simulated gastrointestinal fluids, blood plasma and liver microsomes and shows no relevant human-specific metabolites [51]. Therefore, we concluded that it is perfectly suitable and safe for oral administration in humans. Safety was also investigated and proven in rodents and non-rodents in four-week toxicology studies (hemodynamic and respiratory parameters by telemetry), the Irwing test (motor, sensory, autonomic and integrative neurological function) and in a standard safety pharmacology panel including genotoxicity (AMES test, Micronucleus test), immunogenicity (ADA, T-cell mediated immunity) and a receptor screening. After finalization of all these relevant data, RD2 was recently successfully tested in a first-in-human first-in-class phase I clinical study (single ascending dose (SAD) Eudra CT \# 2017-000396-93 and multiple ascending dose (MAD) Eudra CT 2018-002500-14). Both studies are completed and no drug-related adverse events (AEs) and no drug-related severe adverse events (SAEs) have been described.

In conclusion, the most straightforward consequences for drug development programs and clinical trial designs should be that the objective of the treatment must be the eradication or at least drastic diminishment of the toxic species. Once this is achieved, a life-long treatment is neither necessary nor attractive and this suggests trial designs that should reach their endpoints much faster than was envisioned in previous trials.

Therefore, the advantages of a strategy to treat $\mathrm{AD}$ patients with a compound that directly disassembles and destroys toxic replicating $A \beta$ oligomer species by stabilizing $A \beta$ monomers in their native intrinsically disordered conformation is a very promising treatment strategy and may well be 
the only efficient one. Such a treatment strategy does not at all intend to decrease the total A $\beta$ levels in brain, plasma or CSF. It also does not intend to reduce plaque load, although this may be tolerated if achieved. With its mode of action, RD2 is the first anti-prionic drug candidate whose next important step will be a proof of concept in AD patients.

Author Contributions: J.K. and D.W. wrote the manuscript.

Funding: Financial support of D.W. was provided by "Portfolio Technology and Medicine", the HelmholtzValidierungsfonds of the Impuls, the Vernetzungs-Fonds der Helmholtzgemeinschaft and the Alzheimer's Association Part the Cloud: Translational Research Funding for Alzheimer's Disease (PTC) Award Number: 18PTC-19-605853. D.W. was supported by the "Portfolio Drug Research" of the Impuls and Vernetzungs-Fonds der Helmholtzgemeinschaft.

Conflicts of Interest: D.W. is co-inventor of patents covering the composition of matter of RD2. D.W. is also co-founder and co-owner of the company "Priavoid GmbH", which is developing RD2 further for clinical use. This did not have influence on any data evaluation or its interpretation. J.K. declares no competing interests.

\section{References}

1. Andreadis, A.; Brown, W.M.; Kosik, K.S. Structure and novel exons of the human. tau. gene. Biochemistry 1992, 31, 10626-10633. [CrossRef] [PubMed]

2. Goedert, M.; Crowther, R.A.; Garner, C.C. Molecular characterization of microtubule-associated proteins tau and MAP2. Trends Neurosci. 1991, 14, 193-199. [CrossRef]

3. Goedert, M. Tau gene mutations and their effects. Mov. Disord. 2005, 20 (Suppl. 12), S45-S52. [CrossRef]

4. Selkoe, D.J. The cell biology of beta-amyloid precursor protein and presenilin in Alzheimer's disease. Trends Cell Biol. 1998, 8, 447-453. [CrossRef]

5. Campion, D.; Dumanchin, C.; Hannequin, D.; Dubois, B.; Belliard, S.; Puel, M.; Thomas-Anterion, C.; Michon, A.; Martin, C.; Charbonnier, F.; et al. Early-onset autosomal dominant Alzheimer disease: Prevalence, genetic heterogeneity, and mutation spectrum. Am. J. Hum. Genet. 1999, 65, 664-670. [CrossRef] [PubMed]

6. Hardy, J.A.; Higgins, G.A. Alzheimer's disease: The amyloid cascade hypothesis. Science 1992, 256, 184-185. [CrossRef] [PubMed]

7. Hardy, J.; Selkoe, D.J. The Amyloid Hypothesis of Alzheimer's Disease: Progress and Problems on the Road to Therapeutics. Science 2002, 297, 353-356. [CrossRef]

8. Matsunaga, S.; Kishi, T.; Nomura, I.; Sakuma, K.; Okuya, M.; Ikuta, T.; Iwata, N. The efficacy and safety of memantine for the treatment of Alzheimer's disease. Expert Opin. Drug Saf. 2018, 17, 1053-1061. [CrossRef]

9. Snowdon, D.A. Healthy aging and dementia: Findings from the Nun Study. Ann. Intern. Med. 2003, 139, 450-454. [CrossRef]

10. Gandy, S.; Simon, A.J.; Steele, J.W.; Lublin, A.L.; Lah, J.J.; Walker, L.C.; Levey, A.I.; Krafft, G.A.; Levy, E.; Checler, F.; et al. Days to criterion as an indicator of toxicity associated with human Alzheimer amyloid-beta oligomers. Ann. Neurol. 2010, 68, 220-230. [CrossRef]

11. Sengupta, U.; Nilson, A.N.; Kayed, R. The Role of Amyloid- $\beta$ Oligomers in Toxicity, Propagation, and Immunotherapy. EBioMedicine 2016, 6, 42-49. [CrossRef] [PubMed]

12. Forny-Germano, L.; Lyra e Silva, N.M.; Batista, A.F.; Brito-Moreira, J.; Gralle, M.; Boehnke, S.E.; Coe, B.C.; Lablans, A.; Marques, S.A.; Martinez, A.M.; et al. Alzheimer's disease-like pathology induced by amyloid-beta oligomers in nonhuman primates. J. Neurosci. 2014, 34, 13629-13643. [CrossRef] [PubMed]

13. Walsh, D.M.; Klyubin, I.; Fadeeva, J.V.; Cullen, W.K.; Anwyl, R.; Wolfe, M.S.; Rowan, M.J.; Selkoe, D.J. Naturally secreted oligomers of amyloid beta protein potently inhibit hippocampal long-term potentiation in vivo. Nature 2002, 416, 535-539. [CrossRef] [PubMed]

14. Walsh, D.M.; Klyubin, I.; Shankar, G.M.; Townsend, M.; Fadeeva, J.V.; Betts, V.; Podlisny, M.B.; Cleary, J.P.; Ashe, K.H.; Rowan, M.J.; et al. The role of cell-derived oligomers of Abeta in Alzheimer's disease and avenues for therapeutic intervention. Biochem. Soc. Trans. 2005, 33, 1087-1090. [CrossRef] [PubMed]

15. Olsson, T.T.; Klementieva, O.; Gouras, G.K. Prion-like seeding and nucleation of intracellular amyloid- $\beta$. Neurobiol. Dis. 2018, 113, 1-10. [CrossRef]

16. Cohen, M.; Appleby, B.; Safar, J.G. Distinct prion-like strains of amyloid beta implicated in phenotypic diversity of Alzheimer's disease. Prion 2016, 10, 9-17. [CrossRef] [PubMed] 
17. Walker, L.C.; Schelle, J.; Jucker, M. The Prion-Like Properties of Amyloid-beta Assemblies: Implications for Alzheimer's Disease. Cold Spring Harb. Perspect. Med. 2016, 6, a024398. [CrossRef] [PubMed]

18. Lee, E.B.; Leng, L.Z.; Zhang, B.; Kwong, L.; Trojanowski, J.Q.; Abel, T.; Lee, V.M. Targeting amyloid-beta peptide (Abeta) oligomers by passive immunization with a conformation-selective monoclonal antibody improves learning and memory in Abeta precursor protein (APP) transgenic mice. J. Biol. Chem. 2006, 281, 4292-4299. [CrossRef]

19. Goure, W.F.; Krafft, G.A.; Jerecic, J.; Hefti, F. Targeting the proper amyloid-beta neuronal toxins: A path forward for Alzheimer's disease immunotherapeutics. Alzheimer's Res. Ther. 2014, 6, 42. [CrossRef]

20. Schenk, D.; Barbour, R.; Dunn, W.; Gordon, G.; Grajeda, H.; Guido, T.; Hu, K.; Huang, J.; Johnson-Wood, K.; Khan, K.; et al. Immunization with amyloid-beta attenuates Alzheimer-disease-like pathology in the PDAPP mouse. Nature 1999, 400, 173-177. [CrossRef]

21. Bard, F.; Cannon, C.; Barbour, R.; Burke, R.L.; Games, D.; Grajeda, H.; Guido, T.; Hu, K.; Huang, J.; Johnson-Wood, K.; et al. Peripherally administered antibodies against amyloid beta-peptide enter the central nervous system and reduce pathology in a mouse model of Alzheimer disease. Nat. Med. 2000, 6, 916-919. [CrossRef] [PubMed]

22. Wilcock, D.M.; Rojiani, A.; Rosenthal, A.; Levkowitz, G.; Subbarao, S.; Alamed, J.; Wilson, D.; Wilson, N.; Freeman, M.J.; Gordon, M.N.; et al. Passive amyloid immunotherapy clears amyloid and transiently activates microglia in a transgenic mouse model of amyloid deposition. J. Neurosci. 2004, 24, 6144-6151. [CrossRef] [PubMed]

23. Doody, R.S.; Thomas, R.G.; Farlow, M.; Iwatsubo, T.; Vellas, B.; Joffe, S.; Kieburtz, K.; Raman, R.; Sun, X.; Aisen, P.S.; et al. Phase 3 trials of solanezumab for mild-to-moderate Alzheimer's disease. N. Engl. J. Med. 2014, 370, 311-321. [CrossRef] [PubMed]

24. Salloway, S.; Sperling, R.; Fox, N.C.; Blennow, K.; Klunk, W.; Raskind, M.; Sabbagh, M.; Honig, L.S.; Porsteinsson, A.P.; Ferris, S.; et al. Two phase 3 trials of bapineuzumab in mild-to-moderate Alzheimer's disease. N. Engl. J. Med. 2014, 370, 322-333. [CrossRef] [PubMed]

25. Makin, S. The amyloid hypothesis on trial. Nature 2018, 559, S4-S7. [CrossRef]

26. DiFrancesco, J.C.; Longoni, M.; Piazza, F. Anti-Abeta Autoantibodies in Amyloid Related Imaging Abnormalities (ARIA): Candidate Biomarker for Immunotherapy in Alzheimer's Disease and Cerebral Amyloid Angiopathy. Front. Neurol. 2015, 6, 207. [CrossRef]

27. Ketter, N.; Brashear, H.R.; Bogert, J.; Di, J.; Miaux, Y.; Gass, A.; Purcell, D.D.; Barkhof, F.; Arrighi, H.M. Central Review of Amyloid-Related Imaging Abnormalities in Two Phase III Clinical Trials of Bapineuzumab in Mild-To-Moderate Alzheimer's Disease Patients. J. Alzheimer's Dis. 2017, 57, 557-573. [CrossRef]

28. Tornquist, M.; Michaels, T.C.T.; Sanagavarapu, K.; Yang, X.; Meisl, G.; Cohen, S.I.A.; Knowles, T.P.J.; Linse, S. Secondary nucleation in amyloid formation. Chem. Commun. (Camb.) 2018, 54, 8667-8684. [CrossRef]

29. Meisl, G.; Yang, X.; Hellstrand, E.; Frohm, B.; Kirkegaard, J.B.; Cohen, S.I.; Dobson, C.M.; Linse, S.; Knowles, T.P. Differences in nucleation behavior underlie the contrasting aggregation kinetics of the Abeta40 and Abeta42 peptides. Proc. Natl. Acad. Sci. USA 2014, 111, 9384-9389. [CrossRef]

30. Novo, M.; Freire, S.; Al-Soufi, W. Critical aggregation concentration for the formation of early Amyloid-beta (1-42) oligomers. Sci. Rep. 2018, 8, 1783. [CrossRef]

31. Wolff, M.; Zhang-Haagen, B.; Decker, C.; Barz, B.; Schneider, M.; Biehl, R.; Radulescu, A.; Strodel, B.; Willbold, D.; Nagel-Steger, L. Abeta42 pentamers/hexamers are the smallest detectable oligomers in solution. Sci. Rep. 2017, 7, 2493. [CrossRef] [PubMed]

32. Gremer, L.; Scholzel, D.; Schenk, C.; Reinartz, E.; Labahn, J.; Ravelli, R.B.G.; Tusche, M.; Lopez-Iglesias, C.; Hoyer, W.; Heise, H.; et al. Fibril structure of amyloid-beta(1-42) by cryo-electron microscopy. Science 2017, 358, 116-119. [CrossRef] [PubMed]

33. Stöhr, J.; Condello, C.; Watts, J.C.; Bloch, L.; Oehler, A.; Nick, M.; DeArmond, S.J.; Giles, K.; DeGrado, W.F.; Prusiner, S.B. Distinct synthetic A $\beta$ prion strains producing different amyloid deposits in bigenic mice. Proc. Natl. Acad. Sci. USA 2014, 111, 10329-10334. [CrossRef] [PubMed]

34. Watts, J.C.; Condello, C.; Stöhr, J.; Oehler, A.; Lee, J.; DeArmond, S.J.; Lannfelt, L.; Ingelsson, M.; Giles, K.; Prusiner, S.B. Serial propagation of distinct strains of A $\beta$ prions from Alzheimer's disease patients. Proc. Natl. Acad. Sci. USA 2014, 111, 10323-10328. [CrossRef] [PubMed]

35. Mullard, A. BACE failures lower AD expectations, again. Nat. Rev. Drug Discov. 2018, 17, 385. [CrossRef] [PubMed] 
36. Gold, M. Phase II clinical trials of anti-amyloid beta antibodies: When is enough, enough? Alzheimer's Dement. 2017, 3, 402-409. [CrossRef]

37. Koenigsknecht-Talboo, J.; Meyer-Luehmann, M.; Parsadanian, M.; Garcia-Alloza, M.; Finn, M.B.; Hyman, B.T.; Bacskai, B.J.; Holtzman, D.M. Rapid microglial response around amyloid pathology after systemic anti-Abeta antibody administration in PDAPP mice. J. Neurosci. 2008, 28, 14156-14164. [CrossRef] [PubMed]

38. Weyand, C.M.; Goronzy, J.J. Aging of the Immune System. Mechanisms and Therapeutic Targets. Ann. Am. Thorac. Soc. 2016, 13 (Suppl. 5), S422-S428. [CrossRef]

39. Miller-Vedam, L.; Ghaemmaghami, S. Strain specificity and drug resistance in anti-prion therapy. Curr. Top. Med. Chem. 2013, 13, 2397-2406. [CrossRef]

40. Cummings, J.; Lee, G.; Ritter, A.; Zhong, K. Alzheimer's disease drug development pipeline: 2018. Alzheimer's Dement. 2018, 4, 195-214. [CrossRef]

41. van Groen, T.; Schemmert, S.; Brener, O.; Gremer, L.; Ziehm, T.; Tusche, M.; Nagel-Steger, L. The Abeta oligomer eliminating D-enantiomeric peptide RD2 improves cognition without changing plaque pathology. Sci. Rep. 2017, 7, 16275. [CrossRef] [PubMed]

42. Schemmert, S.; Schartmann, E.; Zafiu, C.; Kass, B.; Hartwig, S.; Lehr, S.; Bannach, O.; Langen, K.J.; Shah, N.J.; Kutzsche, J.; et al. Abeta Oligomer Elimination Restores Cognition in Transgenic Alzheimer's Mice with Full-blown Pathology. Mol. Neurobiol. 2018. [CrossRef]

43. Kutzsche, J.; Schemmert, S.; Tusche, M.; Neddens, J.; Rabl, R.; Jurgens, D.; Brener, O.; Willuweit, A. Large-Scale Oral Treatment Study with the Four Most Promising D3-Derivatives for the Treatment of Alzheimer's Disease. Molecules 2017, 22, 1693. [CrossRef] [PubMed]

44. Schemmert, S.; Schartmann, E.; Honold, D.; Zafiu, C.; Ziehm, T.; Langen, K.J.; Shah, N.J.; Kutzsche, J.; Willuweit, A.; Willbold, D. Deceleration of the neurodegenerative phenotype in pyroglutamate-Abeta accumulating transgenic mice by oral treatment with the Abeta oligomer eliminating compound RD2. Neurobiol. Dis. 2019, 124, 36-45. [CrossRef] [PubMed]

45. Purro, S.A.; Nicoll, A.J.; Collinge, J. Prion Protein as a Toxic Acceptor of Amyloid-beta Oligomers. Biol. Psychiatry 2018, 83, 358-368. [CrossRef] [PubMed]

46. Chen, S.; Yadav, S.P.; Surewicz, W.K. Interaction between human prion protein and amyloid-beta (Abeta) oligomers: Role OF N-terminal residues. J. Biol. Chem. 2010, 285, 26377-26383. [CrossRef] [PubMed]

47. Rosener, N.S.; Gremer, L.; Reinartz, E.; Konig, A.; Brener, O.; Heise, H.; Hoyer, W.; Neudecker, P.; Willbold, D. A d-enantiomeric peptide interferes with heteroassociation of amyloid-beta oligomers and prion protein. J. Biol. Chem. 2018, 293, 15748-15764. [CrossRef] [PubMed]

48. Leithold, L.H.; Jiang, N.; Post, J.; Ziehm, T.; Schartmann, E.; Kutzsche, J.; Shah, N.J.; Breitkreutz, J.; Langen, K.J.; Willuweit, A.; et al. Pharmacokinetic Properties of a Novel D-Peptide Developed to be Therapeutically Active Against Toxic beta-Amyloid Oligomers. Pharm. Res. 2016, 33, 328-336. [CrossRef] [PubMed]

49. Liu, H.; Funke, S.A.; Willbold, D. Transport of Alzheimer disease amyloid-beta-binding D-amino acid peptides across an in vitro blood-brain barrier model. Rejuvenation Res. 2010, 13, 210-213. [CrossRef] [PubMed]

50. Drin, G.; Rousselle, C.; Scherrmann, J.M.; Rees, A.R.; Temsamani, J. Peptide delivery to the brain via adsorptive-mediated endocytosis: Advances with SynB vectors. AAPS PharmSci. 2002, 4, E26. [CrossRef] [PubMed]

51. Elfgen, A.; Hupert, M.; Bochinsky, K.; Tusche, M.; González de San Román Martin, E.; Gering, I.; Sacchi, S.; Pollegioni, L.; Huesgen, P.F.; Hartmann, R.; et al. Metabolic resistance of the D-peptide RD2 developed for direct elimination of amyloid- $\beta$ oligomers. Sci. Rep. 2019, 9, 5715. [CrossRef] [PubMed]

(C) 2019 by the authors. Licensee MDPI, Basel, Switzerland. This article is an open access article distributed under the terms and conditions of the Creative Commons Attribution (CC BY) license (http://creativecommons.org/licenses/by/4.0/). 